\title{
Studies on the Formation of Benzanthrones in Alkaline Anthraquinone Pulping
}

\author{
Pirkko Karhunen and Gösta Brunow \\ Department of Chemistry, University of Helsinki, Vuorikatu 20, SF-00100 Helsinki 10, Finland
}

\begin{abstract}
Karhunen, P. and Brunow, G., 1991. Studies on the Formation of Benzanthrones in Alkaline Anthraquinone Pulping. - Acta Chem. Scand. 45: 945-948.

Loss of anthraquinone (AQ) in alkaline pulping is partly attributed to irreversible reactions of $A Q$ or $A Q$-derived compounds with lignin fragments. 3-(4-Hydroxy-3methoxyphenyl)benz [ $d, e]$ anthracen-7-one, 3-(4-hydroxy-3,5-dimethoxyphenyl)benz$[d, e]$ anthracen-7-one and 3-(4-hydroxyphenyl)benz $[d, e]$ anthracen-7-one have been synthesized and their formation in reactions of isolated lignins has been studied. 2-(4-Hydroxy-3-methoxyphenyl)anthracene-9,10-dione (2-vanillylanthraquinone) has also been prepared.
\end{abstract}

Quinones are well known for their ability to accelerate delignification in alkaline pulping. ${ }^{1,2}$ In particular anthraquinone (AQ) is effective in promoting delignification and stabilizing carbohydrates. ${ }^{1-10}$ The use of anthraquinone as an additive in alkaline pulping is limited by the fact that 'catalyst' cannot be recovered from the spent liquor. ${ }^{7,10}$ The disappearance of AQ from the AQ-AHQ (AHQ = anthrahydroquinone) redox cycle has been explained in part by irreversible reactions of reduced forms of $\mathrm{AQ}$, mainly anthrone (AN), with lignin fragments and carbohydrates. ${ }^{11-13}$ The extent to which the reduced AQ is not converted into AQ has a considerable effect on the economics of the process. To minimize AQ losses, a clearer understanding of the side reaction which the catalyst undergoes during pulping is necessary.

The disappearance of AQ is partly due to the reactions of $\mathrm{AQ}$ or AQ-derived compounds with lignin-derived components resulting the formation of compounds such as benzanthrone (1) and 2-vanillylanthraquinone (4) which have been isolated from alkaline $\mathrm{AQ}$ pulping liquors. ${ }^{12,14,15} \mathrm{To}$ investigate their formation, the substituted benzanthrones 1, 2, 3 and 2-vanillylanthraquinone (4) were synthesized.

Previously benzanthrone 1 has been synthesized by acidcatalyzed condensation of coniferyl alcohol and anthrone followed by oxidative cyclisation. ${ }^{12}$ The methyl ether of 1 was prepared by mixed Ullman reaction. ${ }^{14} 3-(4-\mathrm{Hy}-$ droxy-3,5-dimethylphenyl)benzanthrone was formed in a reaction of anthranol with the quinone methide derived from 1-(4-hydroxy-3,5-dimethylphenyl)-1-propene. ${ }^{16}$ Benzanthrones 2 and 3 are new compounds. 2-Vanillylanthraquinone 4 has not been synthesized before.

\section{Results and discussion}

Syntheses. In the present work, benzanthrones were prepared by the method of $\mathrm{Clar}^{17}$ from the methyleneanthrone 5 and substituted cinnamic acids. When methyleneanthrone reacts with substituted cinnamic acids in nitrobenzene, Diels-Alder products are formed and subsequently dehydrogenated and decarboxylated by reaction with the solvent resulting in the formation of substituted benzanthrones in 8-27\% yield. (Scheme 1).

It was of interest to investigate the reaction of coniferyl alcohol 6 with the methyleneanthrone 5 because both are observed to be present in alkaline AQ cooking liquor: methyleneanthrone is reported to be formed in reaction between anthranol (the enol form of anthrone) and carbohydrates ${ }^{11}$ and coniferyl alcohol is a degradation product of lignin. ${ }^{18,19}$ Coniferyl alcohol 6 did take part in the DielsAlder reaction with methyleneanthrone and the result was the formation of benzanthrones 7 and 1 among other products. From the complicated reaction mixture we succeeded in isolating benzanthrone 7 , a new compound which was identified as its diacetate. Benzanthrone 7 seemed to be

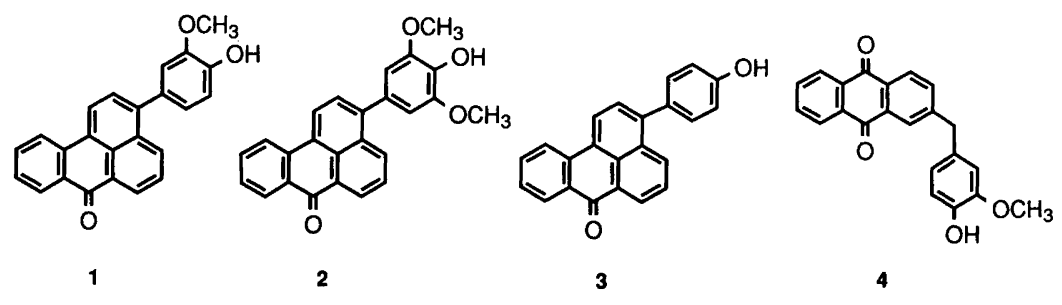




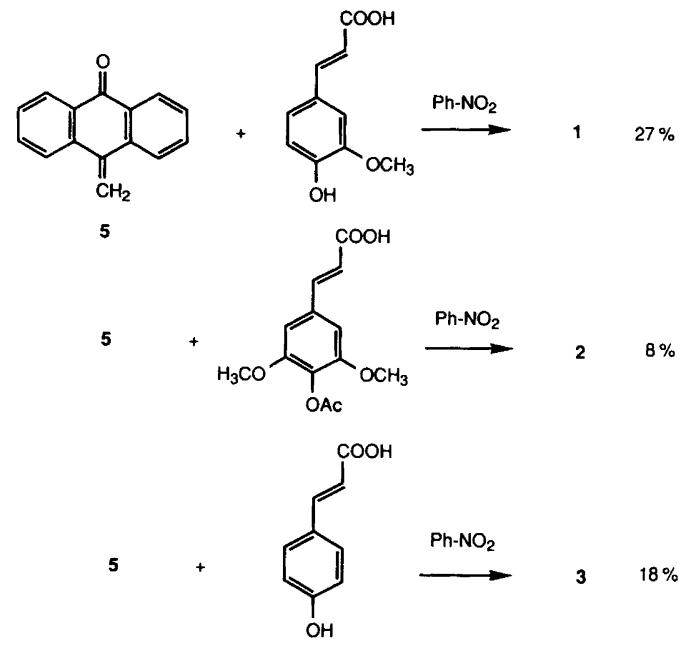

Scheme 1. Syntheses of the substituted benzanthrones 1-3.

one of the main products although pure compound 7 was isolated in only $1 \%$ yield. (Scheme 2 ).

2-Vanillylanthraquinone was synthesized by means of a Friedel-Crafts alkylation reaction involving 2-bromomethylanthraquinone and guaiacol using tin(IV) chloride as the catalyst. ${ }^{20}$ (Scheme 3). A mixture of isomers 4 and 8 was

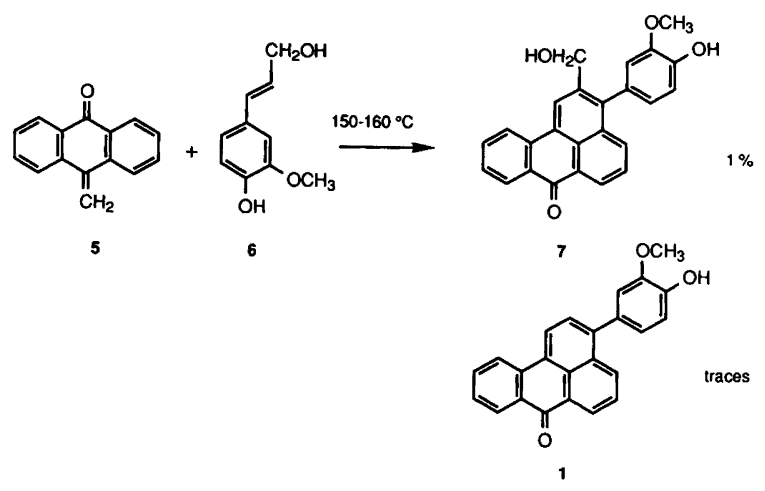

Scheme 2. Reaction of coniferyl alcohol with methyleneanthrone.

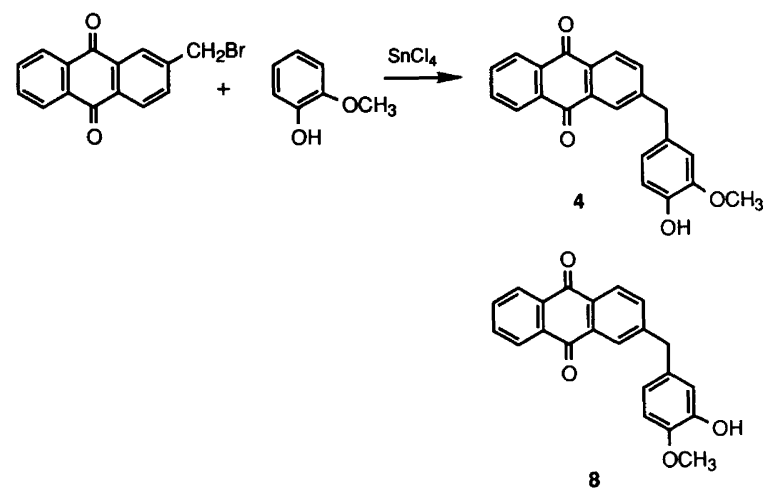

Scheme 3. Synthesis of 2-vanillylanthraquinone. formed in this reaction. The total yield was $30 \%$. The ratio of isomers 4 and 8 was 2:1, as determined by NMR spectroscopy.

Alkaline cookings of isolated lignins. In order to investigate reactions of lignins with AQ-derivatives, isolated lignins (MWL) were allowed to react with the anthrone 9. Benzanthrone 1 was formed in the reaction of spruce lignin and anthrone. The yield was $5 \%$, calculated from anthrone. The benzanthrone 2 was formed in the reaction of birch lignin in $6 \%$ yield. The reaction of straw lignin yielded benzanthrone 2 in $2 \%$ yield and the mixture of benzanthrones 1 and 3 . Compounds 4 and 7 were not detected in any cook. Other anthrone derived products isolated from the reaction mixture were $10,10^{\prime}$-bianthrone 10 (identified as the diacetate of $10,10^{\prime}$-bianthrol) and the unsubstituted benzanthrone 11 in addition to $\mathrm{AQ}$ and anthrone itself. Compound 10 has also been detected in experiments with lignin model compounds and anthrone ${ }^{21,22}$ and compound $\mathbf{1 1}$ has been isolated from alkaline $\mathrm{AQ}$ cooking liquor of wood. ${ }^{15}$

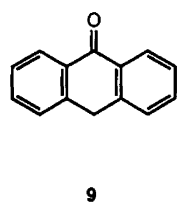

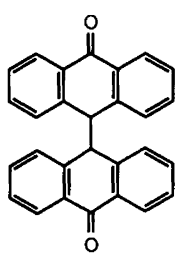

10

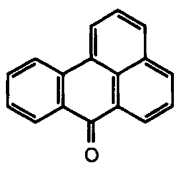

11
The mechanism of the formation of benzanthrone 1 in alkaline AQ cooking conditions has been put forward by Fullerton et al. ${ }^{16,23}$ Their suggestion involves cyclisation and dehydrogenation of a substituted anthrone which is formed in the reaction between anthranol and the extended quinone methide of coniferyl alcohol. An alternative path for formation of benzanthrones 1 and 7 in alkaline cooking conditions might be the Diels-Alder reaction of methyleneanthrone and coniferyl alcohol followed by aromatization since the starting materials are reported to be present in alkaline AQ cooking liquor. ${ }^{11,18,19}$ When a mixture of coniferyl alcohol and methyleneanthrone was heated, the benzanthrone 7 was formed faster and in greater amount than benzanthrone 1 . If the Diels-Alder reaction were the path to formation of benzanthrone 1 in cooking conditions, one would also expect to find the benzanthrone 7 in the spent liquor. However, the absence of the benzanthrone 7 in the cooking liquor of MW-lignin indicates that the DielsAlder reaction is not of importance in the formation of benzanthrones. The direct reaction of anthranol and the quinone methide seems to be more competitive compared with the Diels-Alder reaction. ${ }^{16,23}$ Benzanthrones 2 and 3 can be formed by the same mechanism but probably from sinapyl alcohol and p-coumaryl alcohol. 


\section{Experimental}

The ${ }^{1} \mathrm{H}$ NMR and ${ }^{13} \mathrm{C}$ NMR spectra were recorded on Jeol JNM-PMX 60, Jeol JNM-PFT 100, Jeol JNM-FX 200 FT and Varian Gemini-200 spectrometers. Mass spectra were obtained with a Jeol JMS 01SG-2 instrument.

3-(4-Hydroxy-3-methoxyphenyl)benz [d,e]anthracen-7-one (1). Methyleneanthrone $\mathrm{e}^{17}(309 \mathrm{mg}, 1.5 \mathrm{mmol})$, ferulic acid ${ }^{24}$ (291 $\mathrm{mg}, 1.5 \mathrm{mmol}$ ) and $1 \mathrm{ml}$ nitrobenzene were mixed and refluxed for $1 \mathrm{~h}$. After cooling, $1 \mathrm{ml}$ glacial acetic acid was added and the product was allowed to crystallize over night. The precipitate was filtered and recrystallized from glacial acetic acid. Yield $143 \mathrm{mg}(27 \%)$, m.p. $194-197^{\circ} \mathrm{C}$, (lit. $197-200^{\circ} \mathrm{C},,^{15} 198^{\circ} \mathrm{C}^{12}$ ). The ${ }^{1} \mathrm{H}$ NMR spectrum was in accordance with the literature values. ${ }^{15} \mathrm{UV}$ (abs. ethanol): $\lambda_{\max } 424,286,248 \mathrm{~nm}$. MS $m / z$ (\% rel. int.): 353 (28), 352 (100), 146 (16), 132 (19), 126 (12), 113 (10).

3-(4-Hydroxy-3,5-dimethoxyphenyl)benz [d,e]anthracen-7one (2). Benzanthrone 2 was prepared by the same method as benzanthrone (1) using equimolar amounts of starting materials. The acid in this synthesis was 3-(4-acetyl-3,5dimethoxyphenyl)-2-propenoic acid. During the reaction the acetate was hydrolyzed and the benzanthrone 2 could be isolated from the precipitate. The product was recrystallized from glacial acetic acid. The yield was $8 \%$, m.p. 226-288 ${ }^{\circ} \mathrm{C} .{ }^{1} \mathrm{H}$ NMR $\left(100 \mathrm{MHz}, \mathrm{CDCl}_{3}\right): \delta 3.99(6 \mathrm{H}, \mathrm{s}$, $\left.\mathrm{OCH}_{3}\right), 6.75(2 \mathrm{H}, \mathrm{s}), 7.49-7.86(4 \mathrm{H}, \mathrm{m}, \mathrm{Ar}-\mathrm{H}), 8.34-8.58$ (4 H, m, Ar-H), $8.81(1 \mathrm{H}, \mathrm{dd}, J=1.3 \mathrm{~Hz}$ and $7 \mathrm{~Hz}$ ). IR (KBr): $1648 \mathrm{~cm}^{-1}(\mathrm{C}=\mathrm{O})$. UV (abs. ethanol): $\lambda_{\max } 421,237$, $228 \mathrm{~nm}$. MS $m / z$ (\% rel. int.): 383 (43), 382 (100), 352 (11), 307 (6), 239 (7). Found: $M^{+} 382.1229$. Calc. for $\mathrm{C}_{25} \mathrm{H}_{18} \mathrm{O}_{4}$ : M 382.1200.

3-(4-Hydroxyphenyl)benz [d,e]anthracen-7-one (3). The reaction procedure was the same as described above. 3-(4Hydroxyphenyl)-2-propenoic acid (Fluka AG) was used as starting material. Yield $18 \%$, m.p. $268-271^{\circ} \mathrm{C}$. MS $\mathrm{m} / \mathrm{z}(\%$ rel. int.): 323 (25), 322 (100), 293 (7), 263 (7), 161 (7), 138 (8), 132 (9). Found: $M^{+} 322.1025$. Calc. for $\mathrm{C}_{23} \mathrm{H}_{14} \mathrm{O}_{2}: M$ 322.0190. IR ( $\mathrm{KBr}): 1635 \mathrm{~cm}^{-1}(\mathrm{C}=\mathrm{O})$. UV (abs. ethanol): $\lambda_{\max } 422,242 \mathrm{~nm}$.

2-Hydroxymethyl-3-(4-hydroxy-3-methoxyphenyl)benz[d,e]anthracen-7-one (7). When equal amounts of methyleneanthrone and coniferyl alcohol were heated in a sand bath at $150-160^{\circ} \mathrm{C}$ for $1 \mathrm{~h}$, one of the main products was the benzanthrone 7. Benzanthrone 1 was also formed. When 1 $\mathrm{g}$ of crude product was fractionated by column chromatography (ethyl acetate-cyclohexane 1:3, 1:2 and finally 1:1) $10.4 \mathrm{mg}$ of pure benzanthrone 7 were isolated. M.p. 259$262^{\circ} \mathrm{C}$. MS: no molecular ion. IR $(\mathrm{KBr}): 1630 \mathrm{~cm}^{-1}$ $(\mathrm{C}=\mathrm{O}) .{ }^{1} \mathrm{H}$ NMR $\left(200 \mathrm{MHz}, \mathrm{DMSO}-d_{6}\right): \delta 3.77(3 \mathrm{H}, \mathrm{s}$, $\left.\mathrm{OCH}_{3}\right), 4.53\left(2 \mathrm{H}, \mathrm{d}, \mathrm{CH}_{2} \mathrm{O}, J=5.2 \mathrm{~Hz}\right), 5.45(1 \mathrm{H}, \mathrm{t}, \mathrm{OH}$, $J=5.5 \mathrm{~Hz}), 6.73-8.94(11 \mathrm{H}, \mathrm{m}, \mathrm{ArH}), 9.30(1 \mathrm{H}, \mathrm{s}$, ArOH). ${ }^{13} \mathrm{C}$ NMR (50.10 MHz, DMSO- $\left.d_{6}\right): \delta 55.6$
$\left(\mathrm{OCH}_{3}\right), 60.9\left(\mathrm{CH}_{2} \mathrm{O}\right), 114.0-147.3$ (19 arom. C), 182.7 $(\mathrm{C}=\mathrm{O})$. UV (abs. ethanol): $\lambda_{\max } 412,263,243 \mathrm{~nm}$.

After acetylation (acetic anhydride-pyridine 1:1) the mass spectrum of the diacetate of compound 7 could be recorded. Spectral data of the diacetylated compound 7: MS $m / z$ (\% rel. int.): $466(29), 424$ (M- 42, 100), 365 (17), 364 (39), 349 (21), 334 (10), 333 (29), 321 (36), 305 (17), 276 (10), 263 (12), 43 (58). Found: $M^{+} 466.1460$. Calc. for $\mathrm{C}_{29} \mathrm{H}_{22} \mathrm{O}_{6}: M 466.1410 .{ }^{1} \mathrm{H}$ NMR $\left(200 \mathrm{MHz}, \mathrm{CDCl}_{3}\right): \delta 2.12$ (3 H, s, aliphatic acetyl group), $2.40(3 \mathrm{H}, \mathrm{s}$, aromatic acetyl group), $3.85\left(3 \mathrm{H}, \mathrm{s}, \mathrm{OCH}_{3}\right), 5.16\left(2 \mathrm{H}, \mathrm{s}, \mathrm{CH}_{2}\right)$, 6.93-7.01, 7.20-7.24, (3 H, m, ArH), 7.56-7.84 (3 H, m, ArH), $7.96(1 \mathrm{H}$, dd, $J=1.5 \mathrm{~Hz}$ and $8 \mathrm{~Hz}), 8.39-8.56(3 \mathrm{H}$, $\mathrm{m}, \mathrm{ArH}), 8.76(1 \mathrm{H}, \mathrm{dd}, J=1.5$ and $7 \mathrm{~Hz}$ ).

According to TLC the benzanthrone 7 was also formed when methyleneanthrone and coniferyl alcohol reacted in 1 $\mathrm{M} \mathrm{NaOH}\left(140^{\circ} \mathrm{C}, 3 \mathrm{~h}\right)$ in an autoclave or in nitrobenzene solution.

Cooks with isolated lignins. Experiments were carried out with milled wood lignin isolated from spruce, birch and straw. In each cook $50 \mathrm{mg}$ lignin, $50 \mathrm{mg}$ anthrone and 160 mg glucose were mixed with $0.6 \mathrm{ml}$ dioxane and $2 \mathrm{ml} 1 \mathrm{M}$ $\mathrm{NaOH}$ solution in a stainless steel autoclave. Some experiments were done in a larger scale but the same ratio of reagents and solvents were used. The autoclave was closed and heated at $170^{\circ} \mathrm{C}$ for $3 \mathrm{~h}$. After cooling, the alkaline cooking liquor was extracted with dichloromethane and worked up. The compounds were isolated by column chromatography (ethyl acetate-cyclohexane 1:3-1:1), and identified by TLC and mass spectrometry. The yields are calculated from the amount of anthrone. Benzanthrone 1 was detected in the cooking liquor from spruce lignin, molecular ion $\mathrm{m} / \mathrm{z} 352$. The yield of 1 was $5 \%$. The benzanthrone 11 was also isolated in $8 \%$ yield, molecular ion $m / z 230$. Some fractions were acetylated (acetic anhydride-pyridine $1: 1)$ before recording of the mass spectra. The diacetate of $10,10^{\prime}$-bianthrol was identified, $m / z \quad 470\left(M^{+}\right), 428$ $(M-42)$. The yield of $10,10^{\prime}$-bianthrone 10 was $8 \%$. Birch lignin yielded $6 \%$ of the benzanthrone 2 , molecular ion $\mathrm{m} / \mathrm{z}$ 382. The mixture of benzanthrones 1 and $\mathbf{3}$ was detected in the alkaline anthrone cooking liquor from straw lignin, molecular ions $m / z 352$ (rel. int. $100 \%$ ) and 322 (rel. int. $43 \%$ ). The yield of the mixture was $5 \mathrm{wt} \%$. The benzanthrone 2 was also detected in $2 \%$ yield.

2-(4-Hydroxy-3-methoxyphenylmethyl)anthracene-9,10-dione (2-vanillylanthraquinone) (4). 2-Bromomethylanthraquinone ${ }^{25}(0.5 \mathrm{~g}, 1.7 \mathrm{mmol})$, guaiacol $(5.68 \mathrm{~g})$ and $\mathrm{SnCl}_{4}(0.44$ g) were heated at $100^{\circ} \mathrm{C}$ for $2 \mathrm{~h}$. Ice and $1 \mathrm{ml}$ of $2 \mathrm{M} \mathrm{HCl}$ were added and the product was extracted with ethyl acetate. After work-up, the product still contained catechol which was removed by washing with water. After two flash chromatographic purifications the yield was $30 \%$, m.p. 153-159 ${ }^{\circ} \mathrm{C}$ (lit. ${ }^{15} 150.5-152^{\circ} \mathrm{C}$ ). The ${ }^{1} \mathrm{H}$ NMR spectrum $\left(200 \mathrm{MHz}, \mathrm{CDCl}_{3}\right)$ was in accordance with the literature values ${ }^{15}$ except the methoxy and benzyl protons. Signals 


\section{KARHUNEN AND BRUNOW}

due to methoxy protons at 3.83 and $3.85 \mathrm{ppm}$ and benzylic protons at 4.02 and $4.05 \mathrm{ppm}$ indicate that the product is a mixture of isomers. In the ${ }^{13} \mathrm{C}$ NMR spectrum the ring carbons of the vanillyl substituent in the range 111.2-122.3 ppm gave doublets, which was different from the literature data. ${ }^{15}$ High resolution mass spectrum: Found: $M^{+}$ 344.1070. Calc. for $\mathrm{C}_{22} \mathrm{H}_{16} \mathrm{O}_{4}: M 344.1044$. The most probable isomers are compounds 4 and 8 , the ratio of which was $2: 1$ as calculated from the integrals of the benzylic and methoxy protons.

\section{References}

1. Holton, H. Pulp Pap. Can. 78 (1977) T 218.

2. Wozniak, J. C., Dimmel, D. R. and Malcolm E. W. J. Wood Chem. Technol. 9 (4) (1989) 535.

3. Holton, H. H. US Pat. 4,012.280 (1977); Chem. Abstr. 86 (1977) 157336n.

4. Ghosh, K. L., Venkatesh, V., Chin, W. J. and Gratzl, J. S. TAPPI 60 (11) (1977) 127.

5. Fleming, B. I., Kubes, G. J., MacLeod, J. M. and Bolker H. I. TAPPI 61 (6) (1978) 43.

6. Obst, J. R., Landucci, L. L. and Sanyer, N. TAPPI 62 (1) (1979) 55

7. Algar, W. H., Farrington, A., Jessup, B., Nelson, P. F. and Vanderhoek, N. Appita 33 (1979) 33.

8. Courang, I., Cassidy, R. and Dence, C. W. TAPPI 62 (1979) 43.
9. Löwendahl, L. and Samuelson, O. TAPPI 61 (1978) 19.

10. Cassidy, R. F., Falk, L. E. and Dence, C. W. Svensk Papperstidn. 84 (1981) R 94.

11. Cameron, D. W., Jessup, B., Nelson, P. F., Raverty, W. D., Samuel, E. L. and Vanderhoek, N. The Ekman-Days 198I, Stockholm.

12. Cameron, D. W. and Samuel, E. L. Tetrahedron Lett. (1979) 3035 .

13. Cameron, D. W. and Samuel, E. L. Tetrahedron Lett. 22 (1981) 1841.

14. Fullerton, T. J. and Ahern, S. P. J. Chem. Soc., Chem. Commun. (1979) 457.

15. Fullerton, T. J. and Fleming, B. I. Svensk Papperstidn. 83 (1980) 396.

16. Fullerton, T. J., Hemmingson, J. A., Leary, G. I. and Wright, L. J. J. Wood Chem. Technol. 2 (1) (1982) 383.

17. Clar, E. Chem. Ber. 69 (1936) 1688.

18. Mortimer, R. D. J. Wood Chem. Technol. 2 (1982) 97.

19. Mortimer, R. D. J. Wood Chem. Technol. 5 (1985) 347.

20. Bredereck, K. and Metwally, S. A. Liebigs Ann. Chem. (1974) 1536.

21. Landucci, L. L. and Ralph, J. J. Wood Chem. Technol. 4 (1984) 149.

22. Poppius, K. Acta Chem. Scand., Ser. B 38 (1984) 611.

23. Hemmingson, J. J. Wood Chem. Technol. 2 (1982) 417.

24. Pearl, I. A. and Beyer, D. L. J. Org. Chem. 16 (1951) 216.

25. Blankespoor, R. L., Lau, A. N. K. and Miller, L. L. J. Org. Chem. 49 (1984) 4441.

Received February 4, 1991 